Proceedings

\title{
A New Affordable Masonry System Based on Unfired Clay Sandwich Panel ${ }^{+}$
}

\author{
Sofía Mobili, Carmen Galán-Marín and Carlos Rivera-Gómez * \\ Departamento de Construcciones Arquitectónicas 1, Escuela Técnica Superior de Arquitectura, \\ Universidad de Sevilla, Avda. Reina Mercedes, 2, 41012 Seville, Spain; sofiamobili@gmail.com (S.M.); \\ cgalan@us.es (C.G.M.) \\ * Correspondence: crivera@us.es; Tel.: +34-954-556871 \\ + Presented at the Economy, Sustainable Development and Energy International Conference (ESDEIC), \\ Edinburgh, Scotland, UK, 25-27 June 2018.
}

Published: 30 October 2018

\begin{abstract}
Nowadays, construction is one of the main sectors that produces waste and consume more materials and energy, so there is a growing need for alternative construction technologies that allow us to modify this situation. In this context, this paper presents the development of an innovative proposal for an industrialized outdoor enclosure. This solution is based on a constructive system with prefabricated insulated sandwich panels, produced on the basis of a new eco-efficient composite material, based on raw stabilized clay. In this way, it is possible, prioritize environmental issues to significantly reduce the environmental impact generated during the manufacture of the piece. The use in the construction of buildings material such as stabilized raw clay can be an alternative to achieve buildings of nearly zero energy consumption. They are known both from a thermal comfort and ability to regulate temperature and humidity, as well as being materials that contain much less embodied energy. This study is a comparative analysis of building systems, as well, as a serie of selected patent systems and copyrighted materials. On the other hand, it also analyzes their enforcement against the values established by the Spanish building code.
\end{abstract}

Keywords: raw earth; façade solutions; sandwich panel; sustainability; raw materials

\section{Introduction}

The development of raw land construction is today one of the most important fields of research in the area of ecological materials. In fact, these materials contain much less embodied energy and are, therefore, an alternative of great interest. In addition, they are known for their great ability to regulate temperature and humidity inside buildings.

The research carried out proposes the improvement of the intrinsic properties of the material: the mechanical resistance, the behaviour against water and humidity, as well as the development of innovative proposals for exterior closure systems that respect the environment.

\subsection{Energy Consumption, Energy Efficiency and Sustainable Construction}

Unlike other species, humankind only cares about immediately meeting their "needs" without worrying about what can cause exhaustion and the collapse of the ecosystem [1-3]. The construction sector is one of the main responsible for the depletion of resources and environmental damage. Records show that the construction activities are responsible for exploit and consume around $40 \%$ of natural resources such as stone, sand, wood and water [4].

In environmental terms, this industry represents $30 \%$ of carbon dioxide emissions. In addition, the global construction industry consumes more raw materials (around $3000 \mathrm{Mt} / \mathrm{year}$, almost $50 \%$ by 
weight) than any other economic activity. The construction with earth assumes, in this particular context, an environmental advantage that makes it extremely competitive when compared to conventional materials and current construction techniques [5].

Several researchers have pointed out in recent publications, such as C. Thormark [6], that an appropriate choice of building materials and techniques can mean a $17 \%$ reduction in the energy of a building. There are also several investigations such as the publication by Arrigoni, Beckett, Ciancio and Dotelli [7], which show studies to evaluate the environmental impact of the life cycle of the stabilized raw earth.

\subsection{Architecture of Earth and Industrialization}

Prefabrication means one more step towards the modernization of the construction of the land, as well as helping to find alternatives that bring us closer to sustainability [8]. If we consider that we are talking about manufacturing elements to assemble, the consumption of energy and generation of waste is reduced; there are greater quality controls of the product; they can be dismantled, once their useful life has been exceeded [9].

Industrialization in raw earth production would allow the rationalization of construction costs and execution times, the control of aspects such as the dosage of soil and water, the quality of the execution, the degree of compaction and the final finish [8].

Recent research shows the possibility of applying scientific knowledge and experiences developed in the construction industry based on concrete to earth construction. Some attention has been paid to the necessary adjustments for cement simulation using biopolymers such as alginate or together with a combination of hydraulic binders and additives [10].

On the other hand, non-conventional processing methods have been presented and studied to simplify the construction with soil and reduce time. A current trend in construction is to introduce a digital base in construction methods such as 3D printing [10]. These investigations show that one of the oldest building materials in the world can be applied to new construction processing techniques.

This paper presents the results of the design of an experimental proposal of prefabricated insulating sandwich panels, designed to solve the building exterior closing.

\section{State of the Art}

The work starts from the hypothesis that to be able to propose new designs is necessary to know the existing solutions. A selection of patents of registered systems that represent an evolution in this field was made.

Many examples consist of blocks or composite panels, based on fired clay or ceramic. Other blocks designed for the construction of self-supporting walls are also known, which contemplate the incorporation of the facilities and pipes. The patents include constructive solutions of easy handling and placement to reduce construction times.

They present elements that can provide better performance. They also incorporate the use of plant materials in the production of parts, highlighting their low cost and environmental impact. However, these solutions do not meet the demands of saving energy and resources, nor can most of them meet the necessary thermal and acoustic requirements.

\section{Composite Panel}

\subsection{Shape and Geometry}

With the aim of proposing an innovative solution, composite panels with an innovative shape and geometry were designed. The panel has a rectangular shape consisting of two parts of stabilized raw clay that make up the external faces of the panel, linked together by the insulating material, also used as an adhesive that completes the panel. A value of approximately $450 \mathrm{~mm}$ was adopted for the height, for the length, a measure between 600 and $650 \mathrm{~mm}$ and variable thickness.

The inner sheet has a variable thickness that should not be less than 4 times the thickness of the outer face. It is provided with vertical reinforcements to give greater resistance to compression to the 
piece. The outer leaf has characteristics similar to the interior. It is also constituted by a layer of uncooked stabilized clay. In this case, the piece has different thicknesses to the inner sheet.

The intermediate layer is made of insulating material. Its thickness must be enough to be able to support the weight of the overlapping panels.

\subsection{Materials}

The composite material used in the production of these panels results from a combination of clay soil, water, calcium alginate and natural fibers of animal origin.

The soil used has been selected from a study of researchers [11], in which four different types of soil have been identified, which all come from the southern region of Spain, Andalusia.

Alginate is a natural polymer that contributes not only to flexibility and strength, but also has a high water retention capacity, improves viscosity and stabilizes emulsions [12].

Sheep wool is the natural fiber used in sheep's wool, as a reinforcement to improve resistance to compression, bending and shearing and reduce shrinkage. It also contributes to the absorption of water vapor, which can contain up to $30 \%$ of its weight in water without the sensation of humidity.

The intermediate layer is made of insulating material. In this work, it was decided to use injected or rigid polyurethane. However, the panel can accept the use of other insulating materials.

\subsection{Production Technology}

The sheets that form the walls of the panel can be manufactured by an extrusion process. The material, passes through a nozzle specially designed for each type of piece. Also, it is considered as an option for the manufacture of clay pieces, through the molding system. The sheets of raw clay can be completely molded into a rectangular template. After the manufacture of the clay sheets the core of insulating material is inserted.

\section{Evaluation of the Thermal Behavior}

The Spanish construction regulations, Technical Building Code (CTE) [13], include in its II Part the Basic Document of Energy Saving DBHE, whose objective is to achieve a rational use of the energy necessary for the use of buildings. Section 2 of document HE 0 Limitation of energy consumption establishes the characterization and quantification of the demands to which the envelope must respond, limited according to the climatic zone of the locality where they are located and their intended use.

The different sections of the panel present thermal transmittance values below the maximums established by the regulations for any climatic zone in Spanish territory.

\section{Evaluation of Mechanical Behavior}

Although this new constructive proposal is going to be used in walls that do not support load, it is important to guarantee its structural stability against pressure and wind suction, especially in exposed areas, is one of them.

The verifications were carried out in accordance with the calculation procedures established by the Technical Building Code in Section 5.4.4 of the Basic Document of Structural Safety for Masonry (DBSE-F), where the structural concept contemplated is established [13].

The results obtained for the different sections of the wall show that the piece has a good structural behaviour against compression and bending, both for pressure and suction efforts.

\section{Conclusions}

The work presented in this document aims to develop an innovative prefabricated clay sandwich panel solution for exterior enclosure. It is possible to conclude that:

The proposal reveals the characteristics of a prefabricated system such as geometry, dimensions, module, manufacturing process and even a possible assembly system. 
The solution makes it possible to prioritize environmental aspects, considerably reduce the ecological impact generated during the manufacture of the piece.

The thermal behavior of the proposal is clearly better than most traditional solutions. The approximate calculations made show that the panel complies with the requirements established by Spanish regulations.

The analysis of the mechanical behavior of the solution allows establishing that the proposal is capable of withstanding the efforts to which a traditional enclosure wall is currently subjected.

The solution proposes the reformulation of clay as a traditional material and its incorporation into industrialized construction systems. From the tests carried out, it is evidenced that this material admits its industrialization.

The geometry and design of the panel allowed to reduce the quantities of non-reusable waste, the number of assembly operations and the times of the execution processes.

Author Contributions: S.M., C.G.M. and C.R.G. conceived and designed de prototype; S.M. performed the calculations and analyzed the results; S.M. wrote the paper.

Acknowledgments: The authors wish to acknowledge the IUACC "Instituto Universitario de Arquitectura y Ciencias de la Construcción" for the necessary support to develop this research. We would also like to express our gratitude to the Foundation INNOVARCILLA, also known as the Andalusian Ceramics Technology Centre. This research project and the cost to publish in open access have been partially funded by the TEP-1988 project PANEL of the 2012 call of the Dirección General de Investigación, Tecnología y Empresa. Conserjería de Economía, Innovación, Ciencia y Empleo. Junta de Andalucía.

Conflicts of Interest: The authors declare no conflicts of interest. The founding sponsors had no role in the design of the study; in the collection, analyses, or interpretation of data; in writing of the manuscript; and in the decision to publish the results.

\section{References}

1. Arrigoni, A.; Grillet, A.C.; Pelosato, R.; Dotelli, G.; Beckett, C.T.S.; Woloszyn, M.; Ciancio, D. Reduction of rammed earth's hygroscopic performance under stabilisation: An experimental investigation. Build. Environ. 2017, 115, 358-367, doi:10.1016/j.buildenv.2017.01.034.

2. Stern, N. The Economics of Climate Change. Am. Econ. Rev. 2008, 98, 1-37, doi:10.1257/aer.98.2.1.

3. IPCC. Climate Change 2007: Impacts, Adaptation and Vulnerability: Contribution of Working Group II to the Fourth Assessment Report of the Intergovernmental Panel on Climate Change; Cambridge University Press: Cambridge, UK, 2007; doi:10.1256/004316502320517344.

4. Bragança, L.; Mateus, R. Tecnologias Construtivas para a Sustentabilidade da Construção; Edições Ecopy: Ermesinde, Portugal, 2006.

5. Pacheco-Torgal, F.; Jalali, S. Earth construction: Lessons from the past for future eco-efficient construction. Constr. Build. Mater. 2012, 29, 512-519, doi:10.1016/j.conbuildmat.2011.10.054.

6. Thormark, C. The effect of material choice on the total energy need and recycling potential of a building. Build. Environ. 2006, 41, 1019-1026, doi:10.1016/j.buildenv.2005.04.026.

7. Arrigoni, A.; Beckett, C.; Ciancio, D.; Dotelli, G. Life cycle analysis of environmental impact vs. durability of stabilised rammed earth. Constr. Build. Mater. 2017, 142, 128-136, doi:10.1016/J.CONBUILDMAT.2017.03.066.

8. Mag, M.; Rauch, A. Rammed earth walls and its industrialization (formwork and framing systems). Informes de la Construccion 2011, 63, 35-40.

9. Tenorio, J.A.; García Roll, J.L.; Rios Tolmos, J.; Sorribes Gil, M.; Pinto, M. Industrialización del Proceso Constructivo; Asoc. Española Para La Calid.: Madrid, Spain, 2013.

10. Perrot, A.; Rangeard, D.; Courteille, E. 3D printing of earth-based materials: Processing aspects. Constr. Build. Mater. 2018, 172, 670-676, doi:10.1016/j.conbuildmat.2018.04.017.

11. Galán-Marín, C.; Rivera-Gómez, C.; Petric, J. Clay-based composite stabilized with natural polymer and fibre. Constr. Build. Mater. 2010, 24, 1462-1468, doi:10.1016/J.CONBUILDMAT.2010.01.008. 
12. Rivera-Gómez, C.; Galán-Marín, C.; Bradley, F. Analysis of the influence of the fiber type in polymer matrix/fiber bond using natural organic polymer stabilizer. Polymers 2014, 6, 977-994, doi:10.3390/polym6040977.

13. Ministerio Vivienda; Ministerio de Fomento. CTE Código Técnico de la Edificación, (n.d.). Available online: http://www.codigotecnico.org/ (accessed on 21 June 2018).

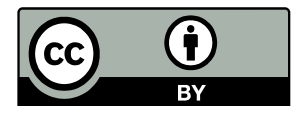

(C) 2018 by the authors. Licensee MDPI, Basel, Switzerland. This article is an open access article distributed under the terms and conditions of the Creative Commons Attribution (CC BY) license (http://creativecommons.org/licenses/by/4.0/). 